\title{
38 SORRY, BUT IT'S MY BUSINESS!
}

M Wighton' ${ }^{1}$ Mungabareena Aboriginal Corporation

10.1136/bmjspcare-2012-000250.38

Aboriginal people generally do not think about or have much input into their advanced care plans or end of life business. In some areas it was taboo to speak of someone's death or journey to death, whether it was for cultural, personal, or spiritual reasons. With consideration to peoples beliefs and customs, more evidence has shown the need for Aboriginal people to be personally involved in their end of life planning, or as it is called, their "Sorry Business". A program through Mungabareena Aboriginal Corporation was initially developed to support people to:

1. Think about their end of life needs.

2. Talk and discuss ideas and wishes.

3. Act upon personalising a plan through practical application.

The program aims to bring together clients and families, service providers and community people over a period of time, allowing information and discussion to be exchanged in a positive way. Groups and individual sessions are held allowing participants to gain information and share thoughts and experiences. The positive outcomes have been the desire for Aboriginal people to have personal involvement in their care plans and own Sorry Business. End of life choices are now known in regards to funeral funds, burials and cremations, organ donations, pets, wills \& estates and other wishes that may be carried out whilst limiting the stress and uncertainty for families. Whilst primarily focusing on the elderly and the sick, the long term goal would be to see all Aboriginal people give consideration to their own "Sorry Business". 